\title{
Consideraciones sobre cirugía del glaucoma y técnica anestésica. Sobre editoriales, revisiones científicas y posibilidades de citación
}

\section{Glaucoma surgery and anaesthetic techniques. On editorials, scientific reviews and citation possibilities}

\section{Sr. Director:}

Hemos leído con mucha tristeza y desencanto, y desde luego con muchísima sorpresa la respuesta que el Prof. Luis Pablo, la licenciada en Medicina y Cirugía Luisa Gómez y la Dra. en Medicina y Cirugía Susana Pérez-Oliván, de Zaragoza, han enviado a la sección de cartas al director, en relación a nuestro editorial titulado "Anestesia local en cirugía del glaucoma", cuyos autores son el Dr. Antonio Alberte, la Dra. Mar Brieba, Dr. Sergio Del Rio, y Dr. Fernando García de la sección de glaucoma del Hospital Costa del Sol en Marbella y por la Dra. M. ${ }^{a}$ Dolores Pinazo-Durán, del Hospital Universitario Dr. Peset de Valencia.

Señor Director, con todo respeto le ruego tenga a bien insertar esta carta de réplica en un próximo número de la revista, ya que deseo responder a la carta enviada por los compañeros de Zaragoza, punto por punto:
1) En el editorial en cuestión no se ha realizado un trabajo de revisión o "state of the art" como aseguran los remitentes, sino un editorial para la revista oficial de la Sociedad Española de Oftalmología. Les ruego a los doctores que tengan a bien revisar las normas de publicación de editoriales, y verán que tanto en la longitud como en el estilo, y también en el número de referencias, nos hemos ajustado estrictamente a las mismas.

2) Les aseguro, créanme, que no se refleja en nuestro editorial ningún prejuicio ni complejo en la parte técnica (como aseveran) ni en el fondo ni en la forma de la misma, ni en el propósito que tuvimos al escribirla, que era mostrar libremente nuestra opinión y experiencia en esta sección, como foro de difusión de la oftalmología española. Tengo la sensación de que todo lo que refieren existe solamente en la mente o en el corazón de los autores de esta réplica, ya que 
tanto les ha afectado el hecho de no haber sido citados en este editorial. Miren, yo soy oftalmólogo desde el año 1980, he ejercido en Valencia casi toda mi vida profesional, pero recientemente me trasladé en comisión de servicios al Hospital Punta de Europa, donde he compartido durante cuatro años consulta clínico-quirúrgica de glaucoma con mi amigo y jefe Ignacio Vinuesa. Me llamó la atención su destreza quirúrgica, su facilidad para innovar, su trato con los enfermos y sobre todo su profesionalidad. No me sorprendió su simpatía y espontaneidad, bien conocidas por mí desde muchos años antes. En este contexto también debo incluir su despreocupación por participar en publicaciones y en proyectos, en lo que se llama coloquialmente "figurar". Aun así, la vida te empuja a veces hacia caminos inesperados. Ignacio siempre me comentaba que nuestra misión es facilitar la curación a los pacientes y mejorar su calidad de vida, y no entrar en el ranking de publicaciones con mayores índices de impacto. ¿Lo ven? ¡cómo no me va a sorprender la carta que nos han escrito oftalmólogos que comparten con nosotros intereses comunes en la clínica, cirugía e investigación oftalmológica, y a la vez con objetivos tan dispares!

3) En cuanto al apartado técnico que indican los remitentes, tengo que asegurarles, créanme, que conocemos bien, quizá "más por viejos que por diablos", que las anestesias que no aumenten la presión intraorbitaria y/o intraocular, que no sorprendan con un hematoma inconveniente, que no puedan inducir una reacción vagal o un movimiento indeseado, etc., son indiscutiblemente las más convenientes para afrontar una cirugía antiglaucomatosa. Hay que comprender que hasta la década de los setenta la cirugía del glaucoma se basaba en la inducción de una fístula para comunicar la cámara anterior con el espacio subconjuntival. Para ello se realizaban las esclerectomías de Elliot o de Lagrange, procedimientos laboriosos y plagados de complicaciones. Sin embargo, en 1968 se describieron técnicas que restablecían la filtración, bajo el concepto de cirugía fistulizante. Harms y Cairns dan entrada a la era de la trabeculotomía-trabeculectomía. Mi primer jefe de oftalmología, en el INSALUD, fue el Dr. Diego Díaz Estévez (hijo del profesor Diego Díaz Domínguez), como saben mis coetáneos, ambos implicados en glaucoma desde tiempo inmemorial. Los recuerdo con mucho cariño (descansen en paz), y doy las gracias porque me introdujeron en el mundo del glaucoma que tanto me fascina, y en la cirugía a través del microscopio, cuando hacía muy poco que habían aparecido en el panorama nacional la trabeculectomía y el láser de argón para tratamiento del glaucoma mediante trabeculoplastia, por situar la época. Entonces, y varios años más tarde, toda la cirugía oftalmológica se realizaba bajo anestesia general (exceptuando la "cirugía menor"). Cuántas veces hemos rogado al compañero anestesista que nos disminuyera la presión arterial y vigilara los gases del paciente, porque el ojo se estaba poniendo muy feo en plena operación. Hemos pasado momentos muy malos ante un vítreo intempestivo, o (afortunadamente las menos) ante una terrible hemorragia expulsiva, sin que en ocasiones, nuestra aparente destreza pudiera impedirlo. Todo esto fue un producto con fecha de caducidad, puesto que algo más tarde, entre los años ochenta y noventa, la accesibilidad a la microcirugía intraocular ha favorecido el desarrollo de instrumental y maniobras diferentes, y la posibilidad de negociar y consensuar la técnica anestésica con los especialistas, lo cual hemos hecho, se lo aseguro, en bien de nuestros pacientes, y de nuestras coronarias.

4) Hace ya más de 15 años, efectivamente, que oftalmólogos de todo el mundo han intentado aplicar anestesias no invasivas en cirugía de glaucoma o en los procedimientos combinados de glaucoma-cataratas. A unos se les ocurrió utilizar gel de xilocaína, a otros hemostetas, láminas esponjosas insolubles en agua como gelfoam o espongostán, gasas, torundas, etc., impregnadas en anestésicos locales bien conocidos, con o sin sedación o neuroleptoanalgesia asociadas. Según comentan los oftalmólogos de Zaragoza, su técnica anestésica de no contacto (similar a la tópica aunque prolongando con artefactos el tiempo de exposición) es la elección, sin necesidad de sedación. Es cierto que el Prof. Pablo posee cuatro publicaciones en los últimos 7 años en relación a la anestesia en cirugía del glaucoma con títulos muy semejantes: a) Anestesia tópica versus anestesia de contacto en la trabeculectomía convencional. Estudio prospectivo aleatorizado. Arch Soc Esp Oftalmol. 2003; b) Contact versus peribulbar anaesthesia in trabeculectomy: a prospective randomized clinical study. Acta Ophthalmologica Scandinavica. 2003; c) Contact-topical plus intracameral lidocaine versus peribulbar anesthesia in combined surgery. Randomized clinical trial. J Glaucoma. 2004, y d) Comparison of the efficacy and safety of contact versus peribulbar anaesthesia in combined eye surgery. Ophthalmologica. 2009. Según una búsqueda bibliográfica avanzada mediante Thomson Reuters ${ }^{\circledR}$, el resultado de citaciones mundiales de esos tres últimos artículos es de 3, 2 y 0 citas, respectivamente. Por lo que a mí respecta, me parecen excelentes trabajos del Prof. Pablo, y al parecer su descontento no proviene únicamente de la falta de citación a nivel nacional, lo cual ha podido reflejarse en la carta que nos remite. Entendemos que el no referenciarlo por nuestra parte, aumentase su disgusto, dadas las circunstancias. Es cierto que la comunidad científica a veces no es lo justa que debiera con todos los autores, por mucho que a uno le parezca que su trabajo así lo merece.

5) Y en el párrafo referente a la decepción y dolor que sufren los remitentes por el supuesto de que "... nuestros mismos colegas consideren innecesario analizar, criticar o al menos citar (que no presupone compartir opinión) el trabajo de grupos españoles. Si alguien no desea probar la eficacia o ineficacia de una técnica por el motivo que sea, está en su indudable derecho. Pero quizá sea exigible (¿¿??) a la hora de hacer una revisión sobre el tema que no olvide ninguno (ij!!) de los trabajos que se hayan realizado y publicado aunque los apellidos de los autores no sean sajones". Debo responder que, en principio a mí me duele que presupongan esta actitud por nuestra parte. Por supuesto, salvando los procedimientos legales, la propiedad intelectual es del autor de la misma, y las opiniones e ideas se ajustan a la libertad de expresión. Por ello, y desde la oportunidad que me brinda en este foro el señor Director de Archivos de la SEO, quiero manifestar que es injusto, tremendamente injusto, recriminar a cualquier autor el no citar a alguien, o a un grupo determinado (sea español o 
extranjero), o que no incluya a autores "extra" que no hayan participado activamente en la confección de cualquier trabajo científico (esas largas listas de autores en los trabajos son, al menos sospechosas en algunos casos), y que por no hacerlo se intente descalificarlo sin evidencia alguna. Me reitero en el hecho que he citado al inicio de la carta: que un editorial no es un trabajo de revisión, que tiene limitado el texto y sobre todo las citaciones (últimamente nos ha sido devuelto por los revisores de la sección, un nuevo editorial por sobrepasar en número de cuatro, las citas bibliográficas permitidas). Espero que el resto de autores nacionales e internacionales implicados en cirugía del glaucoma, biotecnología, investigación y anestesia no nos demanden de igual forma su citación obligada en esta sección, porque a mí, que sí he realizado trabajos de revisión encargados por revistas de prestigio, seguro, segurísimo, que alguna vez se me ha olvidado (y estoy bien segura de que se me va a olvidar alguno de los trabajos en el futuro), de aquellos que se hayan realizado sobre el tema, pese a que los apellidos sean bien entendidos por los hispanoparlantes. Además, les confieso que no esperamos que los autores citados nos agradezcan la referencia en nuestro editorial.

6) Desde aquí, animo a los remitentes de la carta a que realicen un trabajo de revisión sobre anestesia en glaucoma y citen a todos los autores de trabajos relacionados con el tema, sin omitir ninguno.

En fin, Prof. Pablo y colaboradores, si Vds. no deseaban que consideráramos un ataque su demanda de citación, lo han conseguido. Les aseguro que estamos de acuerdo con Vds. Nos gusta que nos citen, nos gusta que consideren nuestro trabajo, nos gusta publicar y mostrarlo en foros de opinión, etc. Y les aseguro que la omisión referida no ha sido premeditada. Como Vds. bien dicen, estamos seguros de que su réplica para nosotros ha sido el producto de un mal día, o un desahogo. Por lo tanto lo olvidaremos en breve.

Un afectuoso saludo.

\section{M.D. Pinazo-Durán}

Doctor en Medicina y Cirugía, Especialista en Oftalmología, Profesor Asociado de Oftalmología, Universidad de Valencia, Coordinador general de Investigacion del Departamento de salud Valencia-Peset.

Correo electrónico: pinazo_mar@gva.es 